\title{
Conclusions and outlook
}

\section{Ulrich Müller, Carolina de la Lastra and Juliane Kolsdorf}

The transformation of international (development) cooperation is an openended process with still unclear results. A multifaceted discourse among practitioners, decision makers, researchers, social entrepreneurs and activists accompanies the transition. Graduation of countries from ODA is one element in this discourse and can only be fully understood if it is embedded in the broader picture of change. Other elements are, for instance, the emerging alternative cooperation modes, the changing roles of actors and the new requirements for cooperation ecosystems.

This publication captures at least part of this discourse with the intention of encouraging further exchange of ideas without judging different views, predicting future developments or necessarily preparing decisions. It was with impressive openness that all the contributors in the dialogues and spotlights shared their thoughts and perspectives, while moving on uncertain ground. This was combined with often deep and critical self-reflection on the current experiences of countries and groups of countries.

It is also remarkable how much the concepts articulated coincide, how the participants in the discussions and authors of the spotlights respond to each other, often without knowing what others had stated. Despite the many concerns and risks expressed, acknowledging that the path to the future has not been laid yet and that there is no guarantee that the global cooperation community will be able to overcome the existing challenges and deficiencies in the system, a great openness towards change prevails, together with a general optimism. This is based on a feeling of self-confidence that all have something to offer and something to learn - a genuine knowledge sharing attitude, also reflected in the 2030 Agenda's principle of universality.

The arguments developed in the dialogues and spotlights move from an overall view on the global system in transition and a screening of the traditional development cooperation system with ODA as a central feature to prospects beyond ODA and the challenges to and opportunities for change. These reflections result in a call for a global goals-oriented, knowledge sharing-based partnership of multiple open-minded actors in the future. 


\section{The global system in transition}

To understand the current changes in development cooperation and the role of ODA graduation within these changes, a view on the broader transitions in the global system is necessary. "What we are seeing right now has, to a large extent, to do with fundamental changes outside the aid system." 129

"Some of the biggest challenges we are facing are transnational" 130 and even "global in scope" 131 . The "degree and plurality of environmental changes we are facing" 132 are mentioned by all participants in the dialogues, as well as "megatrends" 133 such as "the issue of migration and refugees" 134 , "frontier technologies, digitalisation" 135 and others that need to be addressed jointly. These global challenges are reflected in global goals agreed by all countries, especially the 2030 Agenda for Sustainable Development.

Countries from the North are experiencing that it is no longer only them who can claim to be frontrunners in innovation. At the same time, they have become aware that they are affected by global issues and that "vulnerability [...] is not only a feature of developing countries or of extremely poor and vulnerable countries"136, as has been seen, for instance, with the Australian forest fires and the impact of the coronavirus crisis. Moreover, it is recognised that "there are significant developmental challenges even in wealthy countries" 137 , particularly with respect to social and economic inequalities. In consequence, "nowadays, the divide between the North and South needs to be transcended"138. In addition, the idea "that economic development goes along with a development of institutions and political regimes towards democracy, participation and human rights" 139 is questioned. "Today, we know [...] that the relationship between economies, societies and nature also needs to be transformed." 140

Emerging economies from the global South are climbing up the income ladder - which is reflected inter alia in the OECD's prognosis of countries soon to graduate from ODA $^{141}$ - and are demanding their share in global power politics.

129 Klingebiel: 92 in this book.

130 Sidiropoulos: 40 in this book.

131 D'Cruz: 98 in this book.

132 Scholz: 33 in this book.

133 Klingebiel: 92 in this book.

134 Ibid.

135 Ibid.

136 Scholz: 33 in this book.

137 Sidiropoulos: 32 in this book.

138 Ragueb Ahmed: 129 in this book.

139 Scholz: 33 in this book.

140 Scholz: 37 in this book.

141 See: OECD 2014 and Introduction 
They are "developing more agency"142 and "feel more empowered to come in with [...] own positions and articulate them"143. This may offer new opportunities, including alternatives in terms of with whom countries align. However, in the multipolar world, the "complexity of issues and challenges" 144 is increasing. Despite their economic progress, many challenges prevail in emerging countries. They still have a "large poor population" 145 and often high levels of economic, regional and social inequality ${ }^{146}$, resulting in opportunity gaps between different parts of society. There is also no guarantee that the path of growth will continue. Examples of stagnation in some countries have coined the idea of a "middle-income trap" 147 , which is important to avoid.

There are also repercussions on multilateralism. A multipolar world "does not necessarily mean that it is going to be easily more multilateral"148. Many observe a crisis of multilateralism. Over the last few decades, a lot of "blindness and double standards" 149 regarding the multilateral rule-based system has been in place. Nationalistic tendencies, the emergence of stakeholders with different values like China and Russia, and political divisions in formerly unanimous blocks have contributed to "the weakening of the multilateral system as we used to know it, its principles, its rules, its institutions, its procedures" ${ }^{150}$. This was aggravated by the fact that "the big guys do not want to play by the rules"151. Peace between rich countries was accompanied by a lot of wars in developing countries - the effects of that "are now falling back down onto us" 152 to the extent that "the current situation is that multilateralism is under attack and unilateralism is on the rise" ${ }^{\prime 153}$. The new plurality also means that "we need to let go of the belief that we are going to develop an entirely harmonised, universal approach to international cooperation" 154 .

142 Sidiropoulos: 44 in this book.

143 Ibid.

144 Klingebiel: 92 in this book.

145 Mao: 52 in this book.

146 See Bokosi/Spiegel: 113 in this book; see also, for example, ODI country study on Chile: Calleja/Prizzon 2019c: 29.

147 Li: 100 in this book; Pavletic/Schrader: 75 in this book. The term usually refers to countries that have experienced rapid growth and thus quickly reached middleincome status, but then failed to overcome that income range to further catch up to the developed countries. See Glawe/Wagner 2016.

148 Sidiropoulos: 44 in this book.

149 Scholz: 43 in this book.

150 Scholz: 33 in this book.

151 Bokosi: 122 in this book.

152 Scholz: 43 in this book.

153 Li: 100 in this book.

154 Sidiropoulos: 36 in this book. 
At the same time, many agree on the importance of the multilateral system. Preserving and strengthening the multilateral rule-based order requires the countries in the North to rethink their role in the world, including the current distribution of power, and gain a new openness to pressure for reform and to change and solutions brought in from elsewhere. It is nothing less than a "paradigm shift in the mindset of all countries and governments" 155 , which includes to not assume that "developmental solutions or knowledge are only a privilege of a group of countries" 156 but to "believe that all countries in the South can be recipients and providers of knowledge and solution"157. Emerging countries from the South - increasingly so after reaching high-income status - may try to find new approaches to work within the current change within the current multilateral system. "We as developing countries have been requesting to play a more meaningful part in the setting of international rules and standards for a while." 158 However, if their demands are not responded to, they will search for and find alternatives. Thereby, patterns of "contested cooperation" 159 have emerged and a regional power such as South Africa works with "China or Russia, who it believes are able to push for change or to create alternative global institutions in parallel, maybe not to replace but to contest the traditional ones"160.

These changes in international relations naturally have an impact on development cooperation systems. In response to global challenges, many donors are increasingly shifting from a country-based allocation of ODA to a "thematic allocation of resources"161 and "a lot of the assistance is being securitised"162. Domestic problems are putting the governments of countries from the North under pressure for national resource allocation. "Altruistic justification"163 has "always been part of the multilateral system of cooperation"164. But with multilateralism being weakened, "more and more countries adopt a short-term perspective or see their national interests as juxtaposed to international cooperation because they understand it as a zero-sum game"165. In many traditional donor countries "development cooperation is not set very high on the national

155 Ragueb Ahmed: 129 in this book.

156 Ibid.

157 Ibid.

158 González: 54 in this book.

159 Sidiropoulos: 34 in this book.

160 Ibid.

161 Klingebiel: 92 in this book.

162 Sidiropoulos: 42 in this book.

163 Scholz: 35 in this book.

164 Ibid.

165 Ibid. 
agenda" 166 and "it has become much more mercantilist, much more interestdriven"167.

At the same time, there is an increasing demand "to 'cross over' development cooperation and to mainstream it in public policies and to social actors"168. "We do talk about linking those fields: development, peace and security, climate and foreign policy [...]. However, in reality, many of us, be it state actors, be it implementing agencies, be it civil society, be it think tanks, are looking into their own silos. In the end, it is a fight about resources in various organisations concerning certain subjects." 169 On the other hand, it is an increasing reality that more and more sectoral ministries are engaging in development issues ${ }^{170}$. This presents new opportunities but at the same time also poses policy coherence challenges. Development cooperation steps out of the 'comfort zone' of a specific policy field into the competed space of national and global political priorities.

"Rethinking or redefining what we mean by development or international cooperation would be of paramount importance" 171 taking into account that "there is a tension between aid in the old paradigm, that is, the poorest, the neediest countries in a grant financing format, vis-á-vis a broader agenda for policy dialogues and pursuit of donors' national interest in wealthier recipient aid countries" $" 172$.

\section{A screening of the traditional development cooperation system}

In this changing global order, development cooperation and ODA in particular are still considered relevant. "People think that ODA continues to be important [...] to alleviate the worry and concern from LDCs or other developing countries." 173 Representatives of the South remind the North about their "responsibility when it comes to their historical commitments in the area of development cooperation" 174 .

Nevertheless, the concept of ODA is under pressure for many reasons. While some argue that "the priorities [...] should be on poverty alleviation, climate change and debt problems" 175 and that ODA is required to address "the

166 Rivero: 163 in this book.

167 Sidiropoulos: 35 in this book.

168 Ayala: 142 in this book.

169 Wehnert: 135 in this book.

170 Küsel: 72 in this book.

171 Prizzon: 88 in this book.

172 Ibid.

173 Li: 104 in this book.

174 Mthembu: 94 in this book.

175 Li: 102 in this book. 
hard core of poverty"176, others state that "development challenges are not only focused towards developing countries anymore" 177 and ask for "conversations on who defines development, and why they define it in this way and not another way" 178 . "ODA in its traditional form was a vehicle to convey two sets of resources: finance and expertise" 179 , but financing is increasingly available through different channels, particularly to upper middle-income countries, and "the real value of communication and sharing within the international development sector has been in the sharing of experience rather than expertise" 180 in a horizontal and collaborative approach. There is a demand from the South, and from the North as well, to "think "beyond ODA" "181, working "more in partnerships to achieve the 2030 Agenda and to move beyond the binary donor-recipient model"182. Therefore, ODA and graduation from it "should be regarded [...] as part of a broader debate on the rationale of the developing cooperation system"183.

However, there are obstacles to such a change. ODA "is a very strict, narrow system of channelling financial resources from the North to the South. That was the idea back in the 60s, after World War II"184. "This makes it very difficult to achieve true partnership ambition. If you give money as a donor, there will be a receiver. That is ODA; that is the system. All of us do not like it, but the logic of the system, in the end, finds its way into our mindsets." 185 . "We are somehow stuck in the old aid paradigm." 186

ODA graduation is part of this strict system with its classification in one of the four stages of development - from least developed countries to low-income, to middle-income and finally to high-income countries - altering step by step the kind of aid received. While graduation from the LDC status entails a heavy loss of trade support and other kinds of concessional lending from multilateral financial institutions, "graduation from ODA for the upper-middle-income countries is not as painful" 187 since these countries no longer depend on aid in financial terms ${ }^{188}$. In this context, it should be kept in mind that graduation and

176 Ibid.

177 Mthembu: 94 in this book.

178 Mthembu: 96 in this book.

179 D'Cruz: 97 in this book.

180 Ibid.

181 Ragueb Ahmed: 128 in this book.

182 Piefer-Söyler: 153 in this book.

183 Klingebiel: 94 in this book.

184 Wehnert: 137 in this book.

185 Wehnert: 134 in this book.

186 Prizzon: 82 in this book.

187 Li: 104 in this book.

$188 \mathrm{Li}$ : 99 in this book. 
exit of donors from determined countries may have similar effects but are different in terms of their finality. The exit is the result of a political decision in a donor country that can be revised or even taken back, while graduation follows an automatism laid down in the rules for development cooperation that does not leave OECD-DAC donors room for choice. While partners can continue to cooperate regardless of graduation, this may mean a shift in the ministries in charge, and it would certainly not contribute to the $0.7 \%$ ODA target anymore.

Part of the criticism also refers to the graduation criterion itself: "the ODA categorisation by income per capita is a metric that maybe makes sense for economists, but it is increasingly being contested"189. "We need to develop a more comprehensive methodology for measuring development because just using GNI per capita is a too simple way to measure a country's development situation"190. "The metrics for graduating [...] are extremely simplistic. They are also part of the old narrative because we all know that a certain level of income per capita does not say anything about real income distribution, and it does not say much about the quality of public services. The need for cooperation and knowledge sharing and, to a certain extent, resource sharing to solve urgent and major problems do not disappear when you reach this level [...], that is a mismatch in criteria." 191 "The concept of 'graduation' is based on a misunderstanding of what the nature of development is. The DAC graduation is based on the idea that a country magically develops when it surpasses for three consecutive years an arbitrary threshold put forward by the World Bank in the eighties, through a methodology that has never been sufficiently explained, nor adequately updated." ${ }^{192}$ Also, "the $0.7 \%$ target ${ }^{193}[\ldots]$ could really be a disincentive for modernising this [international cooperation] system"194. As, globally, the highest number of poor people live in emerging countries, "there have also always been debates in the international community about whether ODA should focus more on poor countries or poor people." 195

Many of the countries in transition "do not accept that category of 'graduation""196. "There are a lot of contradictions in this concept of graduation, which we think is more related to a political concern than to a real technical

189 Sidiropoulos: $37 \mathrm{f}$ in this book.

190 Mao: 58 in this book.

191 Scholz: 36 in this book.

192 van Rompaey: 55 in this book.

193 Refers to the commitment stated by most DAC donors to achieve the target of spending 0.7 per cent of their GNI on ODA measures. For further information, see https://www.oecd.org/dac/stats/the07odagnitarget-ahistory.htm (15.04.2020).

194 Scholz: 34f in this book.

195 Mao: 52 in this book.

196 Rivero: 156 in this book with reference to "most of the Ibero-American countries". 
concern" 197 . When contesting ODA graduation, these countries are not so much concerned about funding, but about "both the connection to international knowledge and the access to financing"198 to address global challenges. "The economy needs to grow to provide more resources, and the country also needs to become more conscious that these areas need to have a higher priority level in the budgetary struggle. We need funds for the environment and climate change, for global public goods in general. Still, technical cooperation is also needed, and in that respect funds and technical cooperation often come hand in hand." 199 Unlike Eastern European countries that have access to EU neighbourhood facilities, most countries in transition to high-income status in other regions "do not have alternative support mechanisms" 200 to close their development gaps.

While in general all those involved in the dialogues think that ODA and the SDGs "go hand in hand" 201 , countries on the way to ODA graduation perceive the risk "that we will not achieve our goals with a lack of support"202 and reflect on the fact that "our graduation has led to us having a conversation at the global level on the issues that matter most: what do we understand as sustainable development, what needs do countries have relating to sustainable development, what are the capabilities and how can we build an international cooperation system that is based on those needs and the capabilities of countries in terms of sustainable development goals that we have commonly agreed to? [...] This is an opportunity for the ODA graduation criteria to be revised and updated in the light of the 2030 Sustainable Development Agenda." ${ }^{203}$ This reflection leads to the question, raised by many of the discussants, of "if the ODA concept is still relevant. And if there are no other, better ways to measure donors' contributions to global challenges, especially also because the SDG 2030 framework is much broader than what the ODA concept would allow as a measure". ${ }^{204}$

Another criticism in ODA graduation relates to the potential loss of strategic partnerships for global goals. "The graduation process means we are kicking the instruments we have for funding international cooperation out of our hands" ${ }^{\prime 205}$, breaking bridges of cooperation, which afterwards will be difficult

197 González: 50 in dialogue 2, p.4; see also the observation by Annalisa Prizzon that graduation from ODA is criticised for "often being a political decision" (Prizzon: 76 in this book).

198 van Rompaey: 57 in this book

199 Ibid.

200 van Rompaey: 49 in this book.

201 Li: 104 in this book.

202 González: 60 in this book.

203 van Rompaey: 62 in this book.

204 Pavletic/Schrader: 82 in this book.

205 Scholz: 39 in this book. 
to reconstruct, and affecting political dialogue. Thus, countries from the North "will lose relevance as international actors" and countries from the South will build new partnerships "with whomever wants to support our national efforts" ${ }^{206}$. "For us, international cooperation is a [...] means for mutual trustbuilding and to address regional and common global challenges. This is something that the donor community should take into account if they really want to leave countries completely on their own and lose that area of policy dialogue and of strengthening multilateralism, and the common ground to work on all the structural and systemic changes that are needed to really enable development at a global level." 207

The implications of graduation for the countries affected, as well as their position in the international and development systems afterwards, remain unclear. "After graduation, when you are a high-income country, how do you position yourself?"208 "We started to ask ourselves: What are the consequences of being graduated from ODA? What are the wider implications? Are we going to be perceived as a 'developed' country now? Are we going to have to give 0.7 per cent of our GDP to others?"209 In that respect, graduation opens questions of identity and alignment: "Uruguay is no longer a middle-income country. Where does it stand in all the political negotiations in the UN, for instance? Where do we align ourselves? Are we a developing country? Are we a developed country? Are we part of the G77? Are we part of the group of middleincome countries? Our graduation from ODA has also led to us living slightly in limbo." 210 "China always said: we are the largest developing country in the world. So, after we have reached high-income status, how should we position ourselves? Also, rethinking China's foreign assistance and its role as a southern partner: would it still be South-South cooperation? There are a lot of questions on this, already now and especially after you have graduated from the ODA list." 211

Graduated and graduating countries also state there is a lack of clarity about the process itself. "There is not a very clear road map for graduation. We do not really know how to cope with that." ${ }^{212}$ Graduation experiences in the past have been negative: "the process of 'graduation' lacked clarity and formality [...and] if we had not had our close relations with Chile, we would not even have been

206 González: 60 in this book.

207 van Rompaey: 61 in this book.

208 Mao: 58 in this book.

209 van Rompaey: 48 in this book.

210 van Rompaey: 57f. in this book.

211 Mao: 58 in this book.

212 González: 50 in this book. 
properly informed until who knows when" 213 . This went hand in hand with the observation that "there was no explicit strategy on the exit from ODA on the part of the government, but there was also no strategy from the DAC donors to support Uruguay during the graduation process" 214 . The whole process has been perceived as "frustrating because it was automatised and unilateral" 15 .

This is acknowledged by traditional donors, too: "three or four years ago, hardly any donor had a strategy on transition in place - probably the only one was the European Commission with the Agenda for Change in 2011"216. This is changing nowadays. In the process of putting an end to development aid, some donors are trying to foster the "ability to hand programmes over to other development partners or to the government without disruption"217 through longterm planning and stakeholder communication. More and more countries are expected to graduate in the coming years. Forthrightly expressed, "the aid system is a 'dying system'. We have a shrinking market because of this middleincome transit: Some of the most important receiving countries are no longer in need of concessional resources, and this is reflected ultimately in their graduation. Therefore, over the next couple of years, the system will 'run out' of business" 18 . "ODA graduation is an area where we as an implementor see very limited prospects of us continuing cooperation in the respective countries." 219 "The fact that assistance cannot be counted as ODA any more in certain countries is a clear disincentive for DFID, BMZ and French development cooperation." ${ }^{220}$ Most of the traditional donors' development policies formally follow the ODA criteria to define their aid's recipients. However, there are also progressive tendencies: “'Beyond ODA' is already very much a normality and part of our daily life [...], particularly in our cooperation with Asia and Latin America [where] we implement various projects which go beyond a classical development cooperation approach.,"221 222

213 van Rompaey: 48 in this book.

214 Ibid.

215 van Rompaey: 49 in this book.

216 Prizzon: 76 in this book.

217 Prizzon: 77 in this book.

218 Klingebiel: 93 in this book.

219 Küsel: 86 in this book.

220 Prizzon: 88 in this book.

221 Küsel: 72 in this book. Other organisations have had similar experiences: "SouthNorth cooperation is already happening at the grassroots level." (Boyaci: 131 in this book).

222 It should be noted here that some interlocutors distinguish between post-ODA and beyond ODA, defining 'beyond ODA' as "everything beyond classical development cooperation" (Küsel: 72 in this book), while others use both terms synonymously. 


\section{Going beyond $O D A$}

Both donors and countries that will soon graduate or have already graduated have developed an emerging "diversification strategy $[. .$.$] to change from de-$ velopment cooperation to a broader concept of international cooperation"223. From some donors' perspectives, the "focus is much more on building capacities, advising on policies or processes. [...] Policy dialogues [...] or building networks between these countries also play an important role"224. "Projects to facilitate the dialogue between the respective partner country and the [donors'] relevant [...] ministries and agencies" 225 are mentioned, too. "At the same time, funding as part of our cooperation becomes far less important". ${ }^{226}$ Others state that it is part of their agenda to "broaden the number of actors that work with development, and also to include technical cooperation" 227 , and that "many of these types or means of collaboration continue even after development cooperation is phased out"228. "We still have ongoing partnerships in areas where we have a comparative advantage, and this is not limited to development cooperation" 229 but increasingly also involves other, thematically focused public ministries and agencies. "Specialised government actors are playing an increasingly less important role because ODA resources are being split up amongst a group of different ministries, different departments." 230 "This is very valuable because you see where the complementarities are and how each and every unit can contribute" ${ }^{231}$, but it also poses the challenge of capacity building to public institutions with little experience in the field of international cooperation. "Regional or global approaches and funds" 232 have a special significance, though they do "not necessarily directly benefit the graduated country. But [by] working with neighbouring countries, cross-border projects [...] can indirectly benefit the country that has already graduated. That was a good way [...] to keep the policy dialogue with development partners open. Regional cooperation is also a learning opportunity for countries that graduated to become development partners themselves if they wish to do so, and in many cases, this is part of their own

223 Küsel: 72 in this book.

224 Küsel: 80 in this book.

225 Küsel: 81 in this book.

226 Küsel: 80 in this book.

227 Rahm: 81 in this book.

228 Ibid.

229 Ibid.

230 Klingebiel: 105 in this book.

231 Pavletic/Schrader: 82 in this book.

232 Küsel: 80 in this book. 
strategy." 233 This is in line with the aim of many donors "to cooperate with 'global partners' and to strengthen them in their global role"234. These strategies are recognised as being linked to "genuine" 235 donor interests, trying to "find a potential win-win situation" ${ }^{\prime 236}$, especially regarding trade and international relations. Donor countries emphasise that "the rationale behind our engagement is important" 237 and that cooperation, including funding, is appropriate even with higher income countries since "those countries play an important role in their regional context both from an economic and a political perspective, but also regarding their contribution to global challenges" ${ }^{\text {"238 }}$.

The countries that have graduated and will soon graduate are also "adjusting [their] strategies to make the most out of the [forthcoming] situation"239. "We are trying to convince our international partners that we need to work together in a more structured manner." 240 "After the graduation, we managed to negotiate with the European Union and we are back in regional cooperation; they have also maintained the funds for our civil society, and we are negotiating a bilateral co-fund to address $[\ldots]$ transition priorities." ${ }^{241}$ "Basically, we are trying to see how we can shift from, for instance, bilateral to bi-regional development cooperation programmes. We are moving towards different mechanisms of cooperating with donor countries. For instance, we are looking at co-financing certain programmes; we are looking at triangular cooperation; we are looking at horizontal programmes. We are also looking at regionalising within Mexico itself, taking a look at regional, sub-regional or subnational programmes, trying to focus on those regions which are most in need within our own country." 242 This means a reorientation and strengthening of existing cooperation facilities. "We are becoming more of an implementation agency, but at the same time we are not losing grasp of political discussions." 243 "In many [...] ministries, there were also institutions established to manage the incoming aid. After all that had been phased out, they needed to find new tasks and many of these institutions are now active in applying for the implementation of [their] own aid projects.

233 Prizzon: 83 in this book.

234 Küsel: 73 in this book.

235 Pavletic/Schrader: 75 in this book.

236 Pavletic/Schrader: 81 in this book.

237 Pavletic/Schrader: 75 in this book.

238 Ibid.

239 González: 51 in this book

240 Ibid.

241 van Rompaey: 58 in this book

242 González: 51 in this book.

243 González: 55 in this book. 
This way, they hope to support other developing countries by using the knowledge they gained through the incoming aid."244

As part of their diversification strategies, both traditional donors and former recipients are also broadening the scope of participating actors. Many are "enhancing their cooperation with the private sector as a third pillar"245. They also "reach out to other groups in society and broaden our way of looking at development so that we could leave a basis for sustainable development with more actors than the government and some civil society organisations. For example, we had more collaboration with trade unions and private companies." ${ }^{246}$ Given the particularly severe and early impact of graduation on non-state actors, development partners are requested to "explore how to support civil society in more diverse and creative ways to enable [them] to continue to tackle global and local rights and development-related issues"247.

In relation to many global public goods, donors work "on several levels: global, regional and bilateral, and we try to often convene and work through multilaterals and joint networks of actors" ${ }^{48}$. Particularly, "one of the key players in a post-ODA setting focusing on global public goods are the multilateral development banks" 249 , whose partnership with bilateral donors "in a postODA setting is of paramount importance" 250 "and something that we will continue to strengthen over the coming years" 251 .

Financial resources are an important issue to be considered in the "beyond ODA' strategy. The Addis Ababa Action Agenda that accompanies the implementation of the SDGs incorporates a greater variety of sources of financing. Key issues in this respect are, for instance, domestic resource mobilisation through improved tax systems $\mathrm{s}^{252}$ and the attraction of private sector funding ${ }^{253}$, transparency and corruption ${ }^{254}$, but also innovative funding mechanisms ${ }^{255}$. Debt remains an issue that needs to be addressed. This includes "capacity-

244 Mao: 53 in this book.

245 Küsel: 73 in this book.

246 Prizzon: 74 in this book.

247 Hayman: 70 in this book.

248 Rahm: 84 in this book.

249 Prizzon: 83 in this book.

250 Ibid.

251 Pavletic/Schrader: 84 in this book.

252 "In cases where the biggest challenge is in raising domestic resource mobilisation, capacity development in tax issues can be very important" (Spiegel: 113 in this book).

253 For the involvement of the private sector, see Boyaci: 139 in this book.

254 Bokosi: 109 in this book.

255 Boyaci: 136 in this book. 
building in debt management" 256 as well as the demand for "an international mechanism to resolve debt" ${ }^{257}$. It should also be noted here that in spite of their strong orientation towards knowledge sharing approaches "financial resources still are an issue for many southern providers" ${ }^{258}$. This also relates to the capacities of the institutional settings for cooperation. However, the discussion on resources should not be limited to finance. Many other resources such as "knowledge, local knowledge or ancestral knowledge, human resources, technical resources and material resources, are all part of this umbrella of resources" ${ }^{259}$.

In fact, what countries in transition most strongly demand is closely related to these other resources. "Aid was never about how much money donors gave to the country. Aid for us has a strategic value that is beyond its economic worth. It is about agenda setting, it is about putting all the people together that can design the best policy to solve a problem. It is about providing for the overall public goods, it is about strengthening capacities, it is not about the money that it brings in but the knowledge and the facilitation role that comes with it." 260 "For those phased out of ODA, [...] aid not only meant financial support but much more. They valued the technical exchange, sharing of experience, learning and management skills development, which came through the aid from traditional donors." ${ }^{261}$ So "we continue to cooperate, continue to exchange and continue to find ways to support each other's development efforts. Technological exchanges, scientific exchanges, student exchanges and so forth are beneficial for everybody. We have many issues to tackle as humanity."262

257 Bokosi: 118 in this book.

258 Ayala: 138 in this book.

259 Ayala: 138; in the same way, Ragueb Ahmed: 137 in this book.

260 van Rompaey: 49 in this book.

261 Mao: 53 in this book.

262 González: 54 in this book. 
The arguments collected so far make clear that practitioners, analysts, researchers, decision makers and other actors in the international (development) cooperation system are currently witnessing an ongoing and deep process of change. When stepping from a participatory to an observational position, as the discussants in the dialogues presented in this book do, they recognise the reality and dimension of this change: "The future of development cooperation is here and it is very different, completely different to the MDG days or even the Logical Framework Approach days. ${ }^{263}$ However, this does not simply mean that international (development) cooperation is passing from one state to another. The future will rather be "much more diverse than what we have been accustomed to" 264 .

This diversity is an answer to "a significant number of societal, geophysical and environmental challenges that we are facing which absolutely require better forms of international cooperation"265. Its framework is the 2030 Agenda for Sustainable Development, whose global principles and goals express various aspects that make up the new system. Firstly, there will be "many more actors but also a much more diverse set of actors" 266 that are "setting up new partnerships"267 "with a participatory approach, with a multi-stakeholder approach and

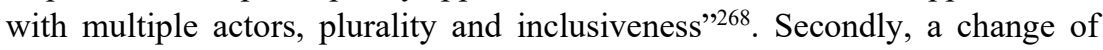
roles and relationships is taking place. The "recipient-donor approach is obsolete and [...the] North and South approach is used less"269. Meanwhile, "all countries in the world should embrace [...a] dual role"270 in which they are "recipients and providers of knowledge and solutions" 271 at the same time. Thirdly, this requires new modes and forms of cooperation. Some of these have already emerged within the development cooperation system and have entered

263 Goni: 161 in this book.

264 Mthembu: 102 in this book.

265 D'Cruz: 101 in this book.

266 Mthembu: 103 in this book.

267 Goni: 161 in this book.

268 Ayala: 132 in this book.

269 Ayala: 133 in this book.

270 Ragueb Ahmed: 129 in this book.

271 Ragueb Ahmed: 129. In the same way, Mthembu: 104: "[...] shifting the narrative away from the idea that there are certain countries that have the knowledge and the know-how; shift away from this donor-recipient view", Piefer-Söyler: 161: "At the same time, experiences of providers of South-South cooperation could be inspiring for DAC members as well", and Wehnert: 130: "[...] in a new world beyond ODA, I do hope that we are all providers, providing ideas and co-creating approaches to global sustainability". 
the 2030 Agenda $^{272}$, for instance the aforementioned multi-stakeholder-partnerships or triangular cooperation that "stands exactly for building bridges between the North and South"273. Other new modes, moreover, have arisen in innovation settings, where "social entrepreneurs [...] create new models" ${ }^{274}$. International (development) cooperation actors need the openness and capacity to recognise these approaches and the ability to incorporate them without spoiling their creative potential.

The increasing diversity provides a lot of opportunities. However, in order to fully unfold these opportunities, a number of requirements need to be met, which can also be seen as challenges to change.

A first requirement lies in the availability of resources for new partnerships, considering the desire to mainstream new modes of cooperation and "the broader perspective of financing for development, of the graduation discussion, of the transition finance discussion" $" 275$. Approaches to change need "to be transferred to existing systems so that more resources can flow into innovation and new models. The problem is that resources are not moving as fast here because it is considered risky." 276 In addition, with respect to triangular cooperation, "people always put the issue of high transaction costs on the agenda. They say it is too complicated to start such a modality; it requires too much investment in terms of coordination, talking and dealing with at least three partners at the same time" 277 . However, "when we talk about transaction costs, we need to think that we are going to deal with transaction costs anyway, because that is what it takes when you form a partnership" ${ }^{278}$. Beyond that, a more radical shift in the provision of resources and the reasons why they are provided is taking place. In a setting beyond ODA, the assessment of cooperation measures will focus less on a beneficiary country, including an exit strategy once local needs have been met, and more on both sides wanting to be part of a partnership, including the willingness to contribute one's own resources in participation. This is a challenge not only for countries from the South but also for countries in the North, where the use of resources has generally been justified according to the help provided to others but not to cover one's own costs. Such partnerships are sustainable when the partners remain involved for a long time and not when the structures created survive without their participation.

272 See especially goal 17 (means of implementation)

273 Walraf: 163 in this book. For more detail on triangular cooperation, see dialogue 7, which especially focuses on South-South and triangular cooperation.

274 Boyaci: 131 in this book.

275 Walraf: 154 in this book.

276 Boyaci: 131 in this book.

277 Walraf: 153 in this book.

278 Goni: 162 in this book. 
A second requirement is the establishment of a new language and a new narrative of development that reflects the changes. Both communities in the systems of North-South cooperation and South-South cooperation need "more dialogue to really understand where we all come from, and what our priorities going forward and our commonalities are"279 in order to get to "broader and more inclusive concepts that translate into equally inclusive financial instruments and cooperation policies" 280 . It requires "a mindset shift for that to happen. And it is not only the mindset that is important, but also the internal institutional regulations, the way we engage in cooperation." 281

This leads to a third requirement, the revision of structures and processes or ecosystems in South-South and triangular cooperation ${ }^{282}$. The issue is "to make sure that the relevant institutional arrangements to absorb the solution and to adapt it to the local context exist. The right legal framework, supporting policies and regulations as well as adequate capacity should be put in place to allow each country to play this role effectively. Without these arrangements, resources and funds will be wasted. It is of paramount importance to strengthen the human and institutional capacities in each country to play these dual roles." 283

\section{Towards a new partnership based on global goals and knowledge sharing}

The reflections on transition in the global system, the past and present practice of development cooperation, and the challenges to and opportunities for change culminate in a vision shared by all the contributors to this publication - with some differences in detail. There is a consensus that the development system needs to go beyond ODA for countries approaching graduation or having graduated and a majority opinion about the characteristics this should have.

This vision has four elements. Content-wise it is oriented towards global goals, predominantly the 2030 Agenda for Sustainable Development. This orientation is based on the conviction that the challenges of the $21^{\text {st }}$ century can hardly be resolved by any country alone, no matter how big and strong it is. In spite of the frequent criticism of the multilateral system, this represents a categorically multilateral vision. The primary practice through which the

279 Piefer-Söyler: 161 in this book.

280 Ayala: 132 in this book.

281 Piefer-Söyler: 153 in this book. The idea of the shift in the mindset is also mentioned by Riad Ragueb Ahmed: 129 in this book.

282 See Islamic Development Bank/ South Center 2019 Developing National Ecosystems for South-South and Triangular Cooperation to Achieve the Agenda 2030 for Sustainable Development

283 Ragueb Ahmed: 133 in this book. 
implementation of the global goals is expected to be fostered is knowledge sharing. While the protection and provision of global public goods particularly will need continued access to funds, knowledge sharing is the way partners, who all have something to contribute and something to learn, find the necessary innovative solutions. In this context, ODA still has its place in supporting those in need, especially low-income countries. Beyond ODA knowledge sharing also requires resources for each country to finance the participation of its own experts. This includes scientific cooperation, but also requires the involvement of policymakers and practitioners. A knowledge sharing-oriented partnership requires $^{284}$ an attitude of openness: in order to listen to the (unexpected) contributions of one's partner, to bring in one's own ideas (with the risk - or chance! - of them being denied or copied) and to accept not necessarily knowing the best solution oneself - to learn from the other ${ }^{285}$. This openness is asked especially from countries from the North.

This vision is not uncontested. Things will not develop in this direction on their own. As regards global goals, the need for collaboration contrasts with the emergence of a new sense of protection of the own group, of the citizens of the own country against all others. This trend has at least partly been nurtured by the fact that globalisation failed to bring about the promised bright future for all people. Therefore, countries from the North may feel tempted to withdraw their cooperation when their own challenges become more pressing. As far as knowledge sharing is concerned, it proves to be a demanding practice. Not everything framed as such really deserves the name due to hidden power relations. A partnership itself is fragile and needs to be re-established continuously, an effort that under conditions of limited resources may be considered too strenuous. Although inspiring and fascinating, openness may also create a fear of losing what has been considered an established right, of being overrun and overruled.

However, the shared vision of a partnership among equals that is geared towards global goals and based on the sharing of solutions and knowledge is not out of reach. Even today, many examples demonstrate how it works in practice. ${ }^{286}$ Whilst the formal rules for official development assistance are clearly set and accepted by most traditional donors, the dynamic cooperation system and the need to confront global challenges have helped it to outgrow its own boundaries. The dialogues in this book show that donor, graduating and graduated countries are taking ground-breaking pathways towards a new de facto situation that invite the cooperation status quo to be amlified and diversified. The

284 Müller 2017.

285 Krewer/Uhlmann 2015.

286 See, for example, cases on triangular cooperation in GPI (2019) and the UN SouthSouth Galaxy (spotlight viii in this book). 
stakeholders have already set their foot in the new reality of international (development) cooperation. The global ecosystem for this cooperation system is growing. It builds upon the principles of development effectiveness ${ }^{287}$ and of South-South cooperation ${ }^{288}$, the experience gained in means of implementation - as expressed in SDG 17 - and the new modes of working together. A new global cooperation ecosystem can transcend the graduation of countries from ODA to the graduation of the international development cooperation system from its existing limitations, leading it beyond ODA.

287 Busan Partnership for Effective Development Cooperation, see 4th High-Level Forum on Aid Effectiveness 2011.

288 'Bandung Conference', see Asian-African Conference 1955. 
